\title{
A MATÉRIA E SUAS TRANSFORMAÇÕES: A RELAÇÃO ENTRE CORPO E MENTE, SEGUNDO DIDEROT
}

Danielly Lima dos Santos

\begin{abstract}
Graduanda do curso de Filosofia da UNESP - Universidade Estadual Paulista "Júlio de Mesquita Filho", no câmpus de Marília. Realiza pesquisas sobre o materialismo na França do século XVIII, sob orientação da prof ${ }^{a}$ dr $^{a}$ Ana Portich. Participa dos grupos de estudos sobre Filosofia da Antiguidade à Renascença, coordenado pelo prof. dr. Reinaldo Sampaio Pereira, e sobre Idealismo, coordenado pelo prof. dr. Lúcio Lourenço Prado, na UNESP de MaríliaE-mail: danielly.santos07.ds@gmail.com.
\end{abstract}

\section{RESUMO}

Neste trabalho, será exposto o materialismo defendido por Diderot n'O Sonho de D'Alembert. Nesse texto redigido a partir de 1769, Diderot trata da relação entre corpo e mente por um viés materialista/monista, explicando como duas coisas aparentemente tão diferentes como o pensamento, imaterial e indivisível, e o corpo, material e divisível, estão conectadas. Descarta diretamente o dualismo substancial cartesiano, deixando claro que tudo é matéria (sensível), e a diferença se dá apenas na sucessiva transformação da matéria de sensibilidade inerte para matéria de sensibilidade ativa. Ou seja, do não inteligente deriva o inteligente. Diderot trata ainda da questão do eu sob um viés materialista e até certo ponto determinista. Diderot compara o eu a um feixe de fios, demostrando qual o processo de transformação que esse feixe de fios passou para chegar à forma atual de feixe de fios: ele era algo imperceptível, formado pelas moléculas de seu pai e sua mãe, tornou-se um fio delgado e depois um feixe de fios. Por umprocesso de nutrição e transformação das moléculas, cada fibra do feixe de fios se transforma em um órgão, extremamente suscetível à sensibilidade. Algumas das sensações percebidas são mais fracas, outras mais marcantes, e para Diderot são essas sensações mais marcantes que darão origem à memória, logo são elas que possibilitam a ideia de um eu. Mas Diderot visualiza o eu como uma ilusão criada por nós, pois, na sucessiva transformação do todo que é a matéria, cada indivíduo é alterado. Participamos desse todo travestido em várias formas, não tendo assim o conhecimento do que seremos daqui a um ano ou um século, por isso é necessário observar o processo de transformações sucessivas por que a matéria passou para chegar à forma atual. Portanto, só podemos conhecer a natureza do pensamento através do processo de transformação da matéria. 
PALAVRAS-CHAVE: Diderot. Iluminismo. Materialismo.

\title{
MATTER AND CHANGES: THE RELATION BETWEEN BODY AND MIND, ACCORDING DIDEROT
}

\begin{abstract}
In this work, the materialism defended by Diderot in D'Alembert's Dream will be exposed. In this text written in 1769, Diderot deals with the relationship between body and mind under a materialistic / monistic bias, explaining how two apparently different things such as the thought, immaterial and indivisible, and the material and divisible body are connected. He directly dismisses the substantial Cartesian dualism, making it clear that everything is matter (sensible), and the difference only occurs in the successive transformation of matter from inert sensitivity to matter of active sensitivity. That is, from the non-intelligent derives the intelligent. Diderot also deals with the Self issue under a materialist, and to some extent deterministic bias. Diderot compares the self to a bundle of wires, demonstrating the process of transformation which this bundle of wires went through, in order to arrive at the present form of bundle of wires: it was something imperceptible formed by its father's and mother's molecules, became a thin wire and then a bundle of wires. Through a process of nutrition and transformation of the molecules, each fiber of the wire bundle becomes an organ, extremely susceptible to sensitivity. Some of the perceived sensations are weaker, others more striking, and for Diderot are those most striking sensations that will give rise to memory, therefore are them who enable the idea of a self. But Diderot sees the self as an illusion created by us, for in the successive transformation of the whole which consists of the matter, each individual is altered. We take part in this transvestite whole in various forms, not having thus the knowledge of what will we be in a year or a century, so it is necessary to observe the process of successive transformations by which the matter has passed to arrive at the present form. Therefore, we can only know the nature of thought through the process of matter transformation.
\end{abstract}

KEYWORDS: Diderot. Enlightment. Materialism.

\section{INTRODUÇÃO}

O intento neste trabalho é expor o materialismo defendido por Diderot n'O Sonho de D’Alembert. Nesse texto redigido a partir de 1769, Diderot trata da relação entre corpo e mente por um viés materialista/monista e ateísta, explicando como duas coisas aparentemente tão diferentes como o pensamento, imaterial e indivisível, e o corpo, material e divisível, estão conectadas, sendo que tal explicação é feita por Diderot através da sensibilidade universal da matéria e de suas sucessivas transformações. Diderot utiliza o mesmo princípio para explicar a 
consciência de um todo, ou seja, a identidade do ser humano.

No “Diálogo entre D’Alembert e Diderot", que faz parte d'O Sonho de D'Alembert, Diderot trata o problema da relação entre mente e corpo, pensamento e matéria, (coisa pensante) e (coisa extensa). Podemos considerar que Diderot, sendo um materialista, irá tratar esse problema, mostrando que ele não existe, é um pseudoproblema, pois tudo é matéria (sensível), ou seja, o pensamento e o corpo são uma única coisa.

D’Alembert começa o Diálogo questionando como algo (pensamento) pode ser e não ser ao mesmo tempo. Afinal, o que é o pensamento? Ocupa espaço? Existe? Se existe, onde e como. É possível fugir do dualismo cartesiano e conseguir explicar como duas coisas, aparentemente tão distintas, estão conectadas? Sendo a sensibilidade entendida por D’Alembert como una e indivisível incompatível com a matéria, que é divisível, ele, portanto, não consegue entender como a sensibilidade (pensamento) pode ser algo compatível com a matéria, e, por isso, insiste na incompatibilidade da sensibilidade com a matéria.

Esse é o grande problema do dualismo substancial (cartesiano), segundo o qual pensamento é imaterial e indivisível, enquanto o corpo é material e divisível. Com essa visão dualista, percebe-se um abismo entre mente e corpo, e isso provoca o questionamento de D’Alembert: como duas coisas tão diferentes podem ser compatíveis?

Para explicar essa propriedade pensante da matéria, Diderot irá mostrar para D’Alembert que um ser pensante, antes de ser um ser pensante, foi um ser sensível, e através de processos mecânicos e bioquímicos esse ser sensível se tornou um ser pensante. Portanto, não há dualismo substancial e sim uma transformação da matéria sensível.

\section{MATÉRIA SENSÍVEL}

Para Diderot a "matéria [é] concebida como realidade única" (SOUZA, 2002, p. 49), afirmando, então, que só existe uma substância no universo e que tudo tem origem na mesma, sendo que dessa substância única (matéria) decorrem todos os fenômenos do mundo, desde a pedra ao homem. Diderot acredita que sua afirmação se confirmará com o avanço da física experimental: "na natureza, reconhecer-se-á, quando a física experimental estiver mais avançada, que todos os fenômenos, [...] são apenas faces diferentes da mesma afecção" (DIDEROT, 1989, p. 64).

Como verificamos no artigo de Claro Castro "Sade entre Epicuro e Zenão", é comum aos materialistas do século XVIII adotarem, como resposta ao dualismo substancial, a tese das 
transformações sucessivas da matéria: "uma reorganização da matéria sob diferentes formatos, consolidara-se como a resposta materialista aos sistemas deístas e cristãos." (CASTRO, 2015, p. 107). Logo, Diderot também aderiu à ideia base da transformações sucessivas da matéria, dessa maneira a matéria inerte seria uma matéria morta, que, ao se organizar, na forma de animal, torna-se matéria ativa, matéria viva; logo entende-se que a matéria não perece, mas se reorganiza e se desorganiza, passando assim por constantes transformações e dando origem a várias formas na natureza; "Nascer, viver e passar é mudar de formas... E que importa uma forma ou outra? Cada forma tem a ventura e a desventura que lhe é peculiar.” (DIDEROT, 1973, p. 401).

Verificaremos também nos Princípios filosóficos sobre a matéria e o movimento de Diderot, que a matéria tem uma força imanente, que a matéria inerte é uma espécie de energia contida e, ao se transformar, ou se preferir, se reorganizar em alguma forma, essa energia é liberada, e a matéria se torna matéria ativa. Portanto, tudo é matéria, e toda matéria tem uma energia inata; e para Diderot o repouso absoluto não existe (toda matéria está em constante movimento), logo, toda matéria está agindo e reagindo constantemente, mesmo que essa ação e reação seja imperceptível para nós: se "todos os corpos gravitam um sobre os outros, é que todas as partículas do corpo gravitam umas sobre as outras, é que, neste universo tudo está em translação" (DIDEROT, 2000, p. 247). De acordo com Clara Castro essa questão também é defendida no materialismo de Sade: onde o corpo, ao se desorganizar, cria uma aparência de perda de movimento, mas na verdade a desorganização do corpo é por si só um grande processo de movimento. "Logo, o movimento é uma propriedade inerente aos elementos primeiros das coisas” (CASTRO, 2015, p. 110), pois o movimento é inerente à substância única: a matéria.

\section{PROBLEMAS DA SENSIBILIDADE UNIVERSAL DA MATÉRIA}

É preciso levar em consideração que para Diderot a matéria tem uma força inerente, que na pedra, por exemplo, é uma força inerte (uma espécie de energia contida), e no homem uma força ativa, (uma espécie de energia liberada): logo, o corpo e o pensamento são na verdade uma única coisa, matéria sensível.

Como D’Alembert questiona se essa sensibilidade (energia) é algo essencial à matéria, o homem (matéria) como a pedra (matéria) deverão possuí-la, o que não é aceitável para D’Alembert, pois o homem aparenta ser um ser constituído de uma essência diferente da pedra, sendo o pensamento a maior expressão dessa diferença. 
Como já ressaltado, Diderot atribuiu sensibilidade a toda matéria, porém veremos que, para Diderot, existem estágios (níveis) da matéria sensível e uma passagem entre os estágios, assim, dá matéria inerte tem-se a matéria ativa e desta à matéria ativa pensante. Portanto, tudo seria resumido a um processo de transformação, passagem ou modificações da matéria sensível: “O ser corpóreo é esse ser, as modificações são o desejo, a aversão, a memória e a inteligência." (DIDEROT, 1989, p. 69).

Essa matéria sensível inerte tem uma espécie de "energia em potencial" (SOUZA, 2002, p. 51) e para Diderot provar a existência de tal sensibilidade (energia) na matéria inerte será necessário mostrar que um corpo de matéria inerte se transforma em um corpo de matéria ativa, ou seja, é necessário "mostrar a liberação da energia que está em potencial." (SOUZA, 2002, p. 51) na matéria inerte.

\section{TRANSFORMAÇÃO DA MATÉRIA: INERTE Á ATIVA}

Isto posto, se essa sensibilidade está presente em toda a matéria e a diferença está na transformação da matéria e em suas respectivas formas, uma estátua (forma aparente de um homem) teria vida/pensamento da mesma maneira que o homem? Ou seja, qual é a diferença entre o homem e a estátua, sendo que a estátua representa a matéria (sensibilidade) inerte, enquanto o homem representa a matéria (sensibilidade) ativa: "Gostaria que me dissésseis que diferença estabeleceis entre o homem e a estátua, entre a mármore e a carne" (DIDEROT, 1973, p. 383).

Diderot afirma que a diferença é mínima, "Da carne se faz mármore e do mármore, carne.” (DIDEROT, 1973, p. 383). A fim de explicar como acontece a transformação da matéria inerte (energia em potencial), para matéria ativa (energia liberada), Diderot apresenta o exemplo da estátua, mostrando o processo de liberação de energia contida na matéria inerte, a estátua. Deste modo, Diderot (1973, p. 384) começa seu exemplo 1) destruindo a estátua, até que ela vire pó, 2) em seguida, mistura o pó da estátua à terra vegetal, 3) em seguida, ele diz: “eu os amasso bem um com o outro; rego a mistura, deixo-a putrefazendo-se um ano, dois, um século, o tempo não importa"; 4) "Quando o todo estiver transformado em uma matéria quase homogênea, [...], sabeis o que faço? [...] Semeio nele ervilhas, favas, couves e outras plantas leguminosas." 5) por fim, quando os legumes estiverem prontos para o consumo, consumimos; 6) ao consumir os legumes, estes últimos se tornam parte do corpo: "As plantas se nutrem da terra e eu me nutro das plantas”. E por esse processo transformamos a matéria inerte, estátua, 
em matéria ativa, parte do corpo (carne), ou seja, é através do processo de assimilação do alimento que a energia em potencial da matéria inerte é liberada, e torna-se, através dessa liberação, matéria ativa.

Essa ideia de transformação da matéria, como podemos ver no texto da Clara Castro, é uma ideia que tem sua origem em Newton, onde ele postula a existência de um "agente vital" que está presente em todos os corpos. Esse agente vital seria o princípio de transformação da matéria morta à matéria viva, em outras palavras, seria a passagem da matéria inerte à matéria ativa: "Newton conclui que é o agente vital que dá coesão às partículas, ordenando-as num agregado vivo. Na morte esse agente quebra as porções de matéria pelo processo de putrefação [...]. Em seguida, ele executa a organização de um novo agregado.” (CASTRO, 2015, P. 115).

Dessa maneira, Diderot mostra que entre a matéria inerte (estátua) e a matéria ativa (carne) há uma continuidade, e que é através da assimilação, junção da matéria em seus diferentes estados, que temos a unidade do animal: "antes da assimilação, havia duas moléculas, após a assimilação não há mais do que uma [...], a fibra será contínua, una... sim, una" (DIDEROT, 1973, p. 394). Ressalte-se que é diferente o contato de duas moléculas de sensibilidade inerte e duas moléculas de sensibilidade ativa, mas "Tudo concorre [...] para produzir uma espécie de unidade, que existe apenas no animal” (DIDEROT, 1973, p. 394). Ou como Maria das Graças de Souza ressalta, essa transformação da estátua em carne é possível pela inexistência de limites definidos entre os estados da matéria: "a natureza não estabelece limites definidos entre os chamados três reinos, e que existe, na verdade, uma circulação dos seres uns nos outros" (SOUZA, 2002, p. 51).

\section{TRANSFORMAÇÃO DA MATÉRIA ATIVA Á ATIVA/PENSANTE: O SURGIMENTO DE UMA "IDENTIDADE" OU UM "EU"}

Sendo assim, podemos considerar que existem dois fenômenos/saltos na continuidade da matéria apresentada por Diderot: um salto é o fenômeno da vida e o outro é o fenômeno do pensamento. Diderot, ao atribuir sensibilidade à matéria e mostrar a transformação da matéria inerte em matéria ativa provou como, através da transformação da matéria um desses saltos/fenômenos, ou seja, como vida, matéria ativa. Resta a ele mostrar como nasce, através dessas transformações, o pensamento, o segundo "salto": "dois fenômenos que [...] são considerados ruptura, [...] na escala contínua, que são o da passagem do inanimado ao vivo e o do surgimento do pensamento." (SOUZA, 2002, p. 59). Pois, como bem pontuado por 
D’Alembert um ser sensível, ainda não é um ser pensante.

É nesse momento que Diderot recusa claramente a explicação da reprodução a partir da teoria da preexistência dos germes e adere à explicação reprodutiva a partir da teoria epigenética, pois “a afirmação do caráter sucessivo da construção do embrião vai permitir situar o aparecimento do pensamento como uma das etapas dessa sucessão.” (SOUZA, 2002, p. 73). Segundo Aullete, epigênese é o "Processo de geração em que o embrião é constituído por uma série de formações novas ou diferenciações sucessivas do ovo ou espermatozoide, sem a preexistência de elementos ou indícios da futura organização do indivíduo:”

Desse modo, para explicar o surgimento do pensamento através das transformações da matéria, Diderot apresenta o exemplo do nascimento de um grande geômetra, D’Alembert, dizendo que a princípio esse ser não era nada, pois antes de seu pai e sua mãe chegarem à puberdade, as moléculas que formaram esse geômetra estavam espalhadas nos corpos de seus pais, desse modo, D’Alembert encontrava-se presente em seu pai e em sua mãe como potencialmente um grande geômetra, e através de um processo mecânico/bioquímico (movimentação, calor, alimentação etc), esse ser, que a princípio não era nada, se tornou um ser sensível e passou a ser também um ser pensante, um grande geômetra.

Ou seja, antes de o homem se tornar uma matéria ativa/pensante ele foi apenas uma massa, matéria inerte, passou de uma desorganização a uma organização básica e da organização básica à uma organização mais complexa, sendo que essa passagem foi realizada através do movimento que produz o calor, e serão esses movimentos que irão gerar a vida, o desejo, a memória, o eu. "Com certa matéria inerte, disposta de uma certa maneira, impregnada de uma outra matéria inerte, do calor e de movimento, obtêm-se sensibilidade, vida, memória, consciência, paixões, pensamento" (DIDEROT, 1973, p. 387).

Essa explicação epigenética da geração dos seres até o surgimento do pensamento é retomada quando Diderot, dando voz ao médico Bordeu, compara o homem a um feixe de fios,explicando que antes de ser um feixe de fios, 1) não era nada, 2) era algo imperceptível, formado pelas moléculas (sensíveis) de seu pai e sua mãe 3) que se tornou um fio delgado e 4) só depois um feixe de fios. Assim, por processos mecânicos e bioquímicos (nutrição e transformação das moléculas em massa, ou se preferir, liberação da energia presente nas moléculas) cada fibra do feixe de fios se transforma em um órgão. Mais uma vez a teoria da epigênese possibilita a Diderot "explicar o pensamento sem recorrer à existência da alma" (SOUZA, 2002, p. 76). 
Segundo Diderot, cada órgão gera mais sensibilidade, de tal modo que o órgão da orelha gera a sensibilidade (tato) da audição, a boca, do paladar, os olhos, da visão, o nariz, do olfato... Essa sensibilidade, que em um primeiro momento é pura e simples, em um segundo momento passa a ser diversificada e complexa. "Mais sentidos, mais necessidades [...]; os órgãos produzem as necessidades, e reciprocamente as necessidades produzem os órgãos." (DIDEROT, 1973, pp. 399-400). Portanto, o feixe de fios é um sistema extremamente sujeito à sensibilidade (frio, dor, amargo), essas sensações são carregadas com menos ou mais intensidade, e as sensações mais marcantes irão se gravar na memória. "Estas impressões sucessivas e variadas entre si, e variadas cada uma em sua intensidade talvez produzissem aí a memória, a consciência de si, uma razão muito restrita.” (DIDEROT, 1973, p. 403).

Desse modo, Diderot entende que o pensamento é a comparação das sensações gravadas na memória e sem essa infinidade de sensações marcantes (em sua maioria não prazerosas) que dão origem à memória, o ser nunca teria a consciência de um eu, uma unidade, um "indivíduo".

\section{O "EU" MATERIAL}

O homem é um ser sensível, mas mais que sensível, o homem é um ser que se sente, se apercebe, um ser pensante, sendo tudo resultado da organização da matéria, logo, se a matéria se desorganizar, o eu se perde, a identidade se esvai: portanto, o eu é matéria! Podemos dizer, então, que Diderot materializa a "alma", pois a dita alma, o dito eu, o cogito cartesiano: é matéria sensível. A intervenção no corpo que pode alterar o eu, é uma das provas que o dualismo substancial é equivocado, e que a suposta alma ou o pensamento, é matéria, ou seja, não é transcendente, é na verdade resultado de um conjunto de órgãos sensíveis presente no homem organizados de uma certa maneira.

Recapitulando, da matéria inerte derivam os fios do feixe, esses fios são as fibras: as fibras são os órgãos, que carregam a sensibilidade ativa, pois os órgãos são afetados em intensidades variadas, as mais intensas serão gravadas na memória; o pensamento está na origem do feixe, e é resultado das comparações de impressões na memória, de sensações variadas em sua intensidade: as relações dessas memórias criarão a história de uma vida.

Essa história corresponde ao eu, um eu que sofreu uma sucessão de alterações, e ainda assim permanece o mesmo, sendo que isso só é possível porque as vicissitudes são lentas; se fossem rápidas não permitiriam ao corpo adquirir memória, relacioná-las/pensá-las. A ideia do eu só é possível pela existência da memória, e pela lentidão das vicissitudes: é essa lentidão que 
possibilita a comparação das memórias, e a criação de uma história de vida (criação de um eu).

Contudo, a perda desse eu é sempre possível, e o ser não precisa sequer perecer para perder essa noção, basta apenas que perca a memória. Essa perda pode ser por um momento breve, ou por todo o resto de sua existência na forma de ser humano: "É preciso um acontecimento bem menor do que a decrepitude para tirar ao homem a consciência do eu" (DIDEROT, 1973, p. 410).

Como prova, Diderot dá o exemplo de um menino com mais ou menos quinze anos, que "caiu do alto de um celeiro; teve a cabeça quebrada e ficou seis semanas inconsciente." (DIDEROT, 1973, p. 410). Essa queda causou-lhe a perda de memória, fazendo-o esquecer de tudo que tinha aprendido até então; o menino voltou a ser criança, consequentemente os homens mais velhos voltaram a lhe ensinar a falar, a ler, a escrever, e até mesmo a andar, e assim transformaram novamente aquele ser com forma de adulto e com mente de criança, em um homem com forma de adulto e mente de adulto. "Desarrumai a origem do feixe e mudareis o animal; parece que este reside aí por inteiro, ora dominando as ramificações, ora dominado por elas" (DIDEROT, 1973, p. 411).

Deixo, você leitor, com a frase que Diderot encerrou o Diálogo "memento quia pulvis es, et in pulverem reverteris." (DIDEROT, 1973, p. 390): Lembra-te de que és pó e ao pó voltarás. 


\section{REFERÊNCIAS BIBLIOGRÁFICAS}

CASTRO, Clara Carnicero de. "Sade entre Epicuro e Zenão". Cadernos de Ética e Filosofia Política, $n^{\circ} 26$. USP, 2015.

DIDEROT, Denis. $O$ Sonho de D'Alembert. Coleção Os Pensadores. São Paulo: Abril Cultural, 1973.

Da interpretação da natureza e outros escritos. São Paulo:
Iluminuras, 1989.

Princípios

filosóficos sobre a matéria $e \quad o$ movimento. Obras I Filosofia e Política. São Paulo: PERSPECTIVA, 2000.

SOUZA, Maria das Graças. Natureza e Ilustração: sobre o materialismo de Diderot. São Paulo: UNESP, 2002.

SANTOS, D.L. A Matéria e suas Transformações: A Relação Entre Corpo e Mente, Segundo Diderot. Complexitas - Rev. Fil. Tem. Belém, v. 3, n. 1, p. 6-15, jan./jun. 2018. Disponível em:< http://www.periodicos.ufpa.br/index.php/complexitas/article/view/6645>. Acesso em: 20 de fevereiro de 2019. 